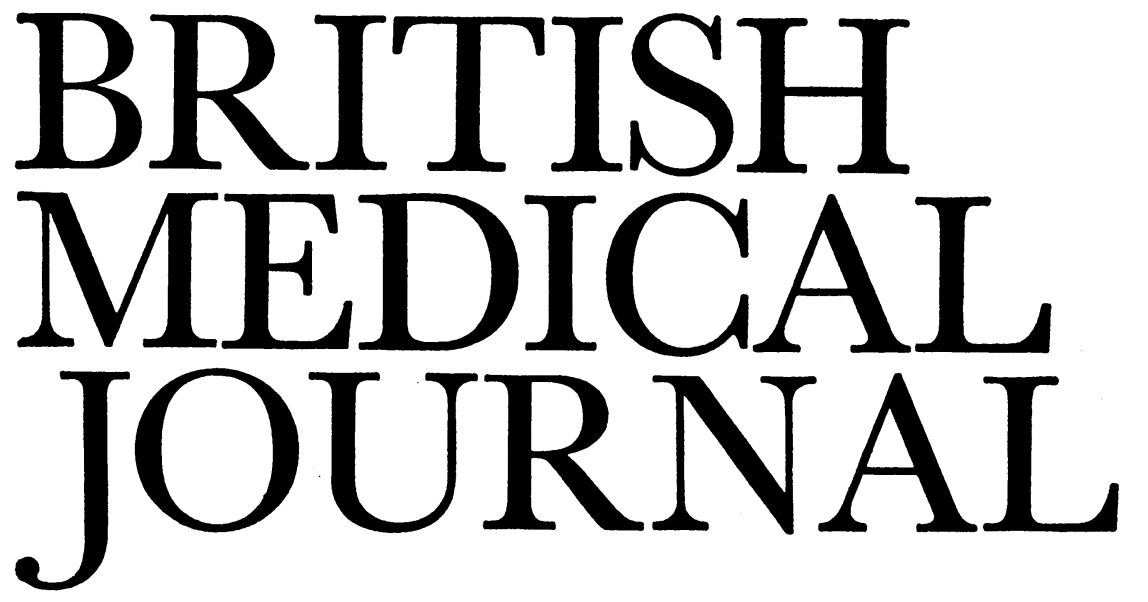

LONDON, SATURDAY 2 APRIL 1977

\title{
New strategies for drug monitoring
}

Attitudes to medicines tend to swing between uncritical enthusiasm about benefits and undue pessimism about risks. Lately the mood swing has been downward, largely because of the practolol episode. ${ }^{12}$ Why were the adverse effects of practolol not detected until four years after it had been released? How can similar mishaps be avoided in future? These questions arose again during two recent conferencesone of invited individuals representing a wide variety of interests held last November at the Royal College of Physicians of London ${ }^{3}$ and the other of experts on monitoring in Honolulu. ${ }^{4}$ At both meetings there was agreement that we urgently need improved methods of drug monitoring.

Surveillance of drugs is indispensable because clinical trials can include only a tiny and possibly atypical fraction of the patients ultimately treated. Once a drug has been released it is vital to determine as quickly as possible whether the risks of continuing use are acceptable in relation to the benefits. We rely at present on two main types of monitoring: voluntary reporting of adverse reactions and intensive hospital monitoring. ${ }^{5}$ Both have serious limitations.

The chief defect of voluntary reporting schemes such as the yellow card system run by the Committee on Safety of Medicines $^{6}$ is that reactions are never reported until doctors suspect that they may be caused by a drug. Even when an adverse reaction has been identified its incidence cannot be estimated reliably because reporting is incomplete and the number of people using the drug is unknown. Intensive hospital monitoring (of which the best example is the Boston Collaborative Drug Surveillance Program ${ }^{7}$ ) has the advantages that adverse events can be recorded whether or not they are suspected to be due to drugs and accurate estimates of incidence are possible. Such monitoring, however, can provide information only about relatively common, early reactions to drug regimens used in hospital. Patients are not in hospital long enough for detection of delayed effects-the reactions least likely to be spotted even by an astute clinician.

At various meetings during the past year Inman has advocated "recorded release" of new drugs; his proposals were presented in detail at the workshop in Honolulu. ${ }^{9}$ Selected drugs would be given a provisional licence for use in recorded patients. Any doctor would be free to prescribe these drugs provided he was prepared to co-operate in the scheme. When a patient was given his first prescription the doctor would send a reply-paid form to the Committee on Safety of Medicines containing a copy of the prescription and basic clinical information. Suspected adverse reactions would be notified in the usual way, but after a suitable period the doctor would be asked to return a second form recording any ailments reported by the patient, with details of referrals or hospital admissions. This would allow estimation of the incidence of adverse events among patients receiving a drug and should lead to identification of a hazard before there was any suspicion that the drug was responsible. Every patient receiving the drug would be studied until sufficient evidence of safety had accumulated for the drug to be recommended for general release. But surveillance would not stop there. Delayed effects could be monitored with the help of the Office of Population Censuses and Surveys, which could tell the monitoring centre whenever recorded patients were notified to a cancer registry or certified as dead.

Similar methods were discussed recently by Dollery and Rawlins. ${ }^{10}$ One feature of their proposal was that the patients themselves would be asked to complete detailed questionnaires about their symptoms. Lawson and Henry ${ }^{11}$ have objected that this would provoke anxiety and suggest a different scheme in which patients receiving new drugs would be recorded by the dispensing pharmacist rather than the doctor.

Each of the methods proposed is an attempt to improve the technique of "monitored release" used by some pharmaceutical companies. Doctors may be expected to welcome any measures that will reduce the risks associated with new drugs. Nevertheless, several questions need to be answered. A serious weakness of all the proposals is that they do not indicate how suitable controls could be chosen for comparison with the patients exposed to a new drug. It would be difficult to interpret the incidence of a particular condition among users of a drug without knowing the incidence (measured by the same methods) among similar people who had not received the drug. Several other questions can be settled only by pilot studies. Would the procedures be acceptable to doctors, patients, and pharmacists ? What would be the quality of the data collected ? Could confidentiality be guaranteed ? How much would each scheme cost? The onus is now on those putting forward the schemes to conduct pilot studies carefully designed to answer these questions.

Recorded release could provide information about a selection of new drugs but not about the thousands of drugs already on the market. Members of the Honolulu workshop were also anxious to know more about existing drugs-and especially to monitor for delayed effects like the induction of cancer. Idänpään-Heikkilä12 described Finnish research in which 
medical record linkage was an integral feature, and the conference recommended that similar facilities should be established in other countries. Britain has ideal circumstances for record linkage, but the opportunities have been sadly neglected. A paper from Oxford, ${ }^{13}$ however, described ways in which linked records could be used to monitor drugs prescribed in general practice. The methods entail a minimum of extra work for family doctors and could be extended to a large population at reasonable cost. A pilot study in a population of 40000 people has nearly been completed.

Fortunately the lesson of practolol is adding fresh impetus to the search for improved strategies for drug monitoring. But no one should imagine that such advances will solve the problem of iatrogenic disease. Most drug-induced illnesses are due to well-known reactions to familiar drugs. ${ }^{14-17}$ Cautious and judicious prescribing is still the key to prevention. Even then some reactions are unavoidable, and patients as well as doctors must realise that no medical treatment can be made entirely safe. Nevertheless, from the glib accounts of many of the lay "experts" in our popular press and in Parliament the average reader would imagine that extensive testing could predict adverse reactions without much difficulty and that somebody is always to blame for a drug tragedy. The truth is that, as with rock climbing or driving fast cars, the use of powerful drugs always carries an inherent risk. One of the virtues of the excellent conference at the Royal College of Physicians was that it brought together laymen, pharmacologists, drug regulating authorities, and prescribing doctors and emphasised the sheer logistical difficulties of recognising adverse effects. With practolol, for instance, dry eye superficially resembled that seen in many old people and was recognised as a specific lesion only in a specialist clinic. Moreover, the use of practolol represented about 250000 patient years, with only some 619 validated adverse reports (including about 20 of near blindness).

The Honolulu conference was also concerned with public attitudes, and Finney emphasised that the public should demand that its elected representatives should press for the fullest possible support for effective drug monitoring. Certainly at present Britain's customary official parsimony extends to our drug monitoring authorities. The Committee on Safety of Medicines' adverse reactions section has four people at headquarters and 60 part-timers in the field: the American FDA has just voted itself another 16.4 million dollars and created an extra 600 posts in an already large organisation. If the band of strident lay experts would turn their attention to pressing the Government to provide this thoroughly praiseworthy organisation with the resources to do the job, they would serve the public interest much better.

1 British Medical fournal, 1975, 2, 577.

2 British Medical fournal, 1976, 2, 1155.

3 Fournal of the Royal College of Physicians, 1977, 11, 000.

4 Gross, F, and Inman, W H W, eds, Proceedings of the International Workshop on the Future of Drug Monitoring for Safety, Honolulu, Fanuary 1977. To be published.

${ }^{5}$ Inman, W $\mathrm{H}$ W, and Vessey, M P, in Recent Advances in Community Medicine, ed A E Bennett. In press.

${ }^{6}$ Inman, W $\mathrm{H} \mathrm{W}$, in Adverse Drug Reactions, eds D J Richards and R K Rondel, p 86. Edinburgh, Churchill Livingstone, 1972.

7 Jick, H, et al, Fournal of the American Medical Association, 1970, 213, 1455.

8 Cohen, M R, Hospital Pharmacy, 1974, 9, 437.

- Inman, W H W, Recorded Release: A Method for Systematic Monitoring of Adversities Associated with Drugs. Paper read at International Workshop on the Future of Drug Monitoring for Safety, Honolulu, January 1977.

10 Do!lery, C T, and Rawlins, M D, British Medical fournal, 1977, 1, 96.

${ }^{11}$ Lawson, D H, and Henry, D A, British Medical fournal, 1977, 1, 691.

12 Idänpään-Heikkilä, J, Use of Population Monitoring-Medical Record Linkage for Drug Safety Surveillance. Paper read at International Workshop on the Future of Drug Monitoring for Safety, Honolulu, January 1977.
13 Skegg, D C G, Possible Methods of Monitoring Adverse Reactions to Drugs in General Practice. Paper read at International Workshop on the Future of Drug Monitoring for Safety, Honolulu, January 1977.

14 Hurwitz, N, British Medical fournal, 1969, 1, 539.

15 Miller, R R, Archives of Internal Medicine, 1974, 134, 219.

${ }^{16}$ Hurwitz, N, and Wade, O L, British Medical Fournal, 1969, 1, 531.

1 Shapiro, S, et al, Journal of the American Medical Association, 1971, 216, 467.

\section{Coronary heart disease and the menopause}

Men are more likely to develop coronary heart disease than women. The fact that this sex difference decreases after the menopause has led to the suggestion that female sex hormones may exert a protective effect. Some studies have shown that women undergoing an early menopause have an increased risk of developing coronary heart disease, perhaps owing to the early loss of their hormonal protection. One of the most recent reports from Framingham ${ }^{1}$ claims to add further evidence of this effect.

The Framingham study has included long-term follow-up of women whose age at the menopause was known and in whom the development of coronary heart disease has been carefully monitored. Overall significantly more "cardiovascular events" occurred in postmenopausal than premenopausal women of the same age. There are, however, difficulties in interpreting these data. The whole report is based on only 90 events, and these include the historical development of angina, intermittent claudication, and congestive heart failure as well as stroke and hard evidence of coronary heart disease (myocardial infarction and coronary death). The inclusion of stroke in the evaluation may be misleading, because at the relevant ages men do not have a higher risk than women, ${ }^{2}$ so that there is no "protection" to lose at the time of the menopause. When restricted to coronary heart disease alone there were only 59 events (probably mostly angina, though we are not told exactly), and the difference between pre- and postmenopausal women was significant only in the 40-44 age group, totalling only six events. In view of the small numbers and the ill-defined nature of the endpoints we would be rash to draw too many conclusions from this study.

The tenuous nature of the association between an early menopause and cardiovascular disease is confirmed by examining some of the original studies on which it was based. Three of the studies compared castrated women (cases) with controls. In one ${ }^{3}$ the age structure of the cases was different from the controls, and in the others ${ }^{45}$ the cases and controls comprised such different sorts of patients that variations in cardiovascular disease could easily be due to factors other than the presence or absence of ovaries. A Swedish study ${ }^{6}$ compared the menstrual histories of women with known coronary heart disease with a random sample of the population. Some $76 \%$ of women admitted to hospital with myocardial infarction had passed through the menopause by the age of 50 or before compared with $48 \%$ of the controls. While this study may be criticised on some points, it provides the best evidence yet of an association between an early menopause and coronary heart disease.

In contrast, there is strong evidence that taking hormones in the form of oral contraceptives increases the risk of developing coronary heart disease. The risk, as determined by two separate studies, ${ }^{78}$ seems to be increased by between 2.8 and 4.7 